\title{
Exosome-enriched fractions from MS B cells induce oligodendrocyte death
}

Joyce A. Benjamins, PhD, * Liljana Nedelkoska, BSc, Hanane Touil, PhD, Paul M. Stemmer, PhD, Nicholas J. Carruthers, PhD, Bhanu P. Jena, PhD, Akshata R. Naik, MSc, Amit Bar-Or, MD,* and Robert P. Lisak, MD*

Neurol Neuroimmunol Neuroinflamm 2019;6:e550. doi:10.1212/NXI.0000000000000550

\section{Abstract}

\section{Objective}

To identify whether factors toxic to oligodendrocytes (OLs), released by B cells from patients with MS, are found in extracellular microvesicles enriched in exosomes.

\section{Methods}

Conditioned medium (Sup) was obtained from cultures of blood B cells of patients with MS and normal controls (NCs). Exosome-enriched (Ex-En) fractions were prepared by solvent precipitation from Sup containing bovine serum and from serum-free Sup by ultracentrifugation (UC) or immunoprecipitation (IP) with antibodies to CD9. Ex-En fractions were diluted 1:4 with OL culture medium and screened for toxic effects on cultured rat OLs as measured by trypan blue uptake. Proteomic analysis was performed on Sup fractions.

\section{Results}

MS B cell-derived Ex-En fractions prepared from Sup by solvent extraction, UC, or IP induced OL death, whereas corresponding Ex-En fractions from NC showed little toxicity. Proteomic analysis of Sup demonstrated enrichment of proteins characteristic of exosomes from both NC and MS B-cell Sup. Ontology enrichment analysis suggested differences in the types and cargo of exosomes from MS Sup compared with NC, with proteins related to cell surface, extracellular plasma membrane, and gliogenesis enriched in MS.

\section{Conclusions}

Much of the in vitro toxicity of Sup from B cells of patients with relapsing-remitting MS is found in Ex-En fractions, as confirmed by 3 methods. Proteomic analysis of B-cell Sup indicates multiple differences between MS and NC.

\author{
Correspondence \\ Dr. Benjamins \\ jbenjami@med.wayne.edu
}




\section{Glossary}

AMBIC = ammonium bicarbonate; DMEM = Dulbecco's modified Eagle medium; DTT = dithiothreitol; Ex-En = exosome enriched; $\mathbf{F D R}=$ false discovery rate; $\mathbf{G M}=$ gray matter; $\mathbf{I A A}=$ iodoacetamide; $\mathbf{I g}=$ immunoglobulin; $\mathbf{I P}=$ immunoprecipitation; NC $=$ normal control; $\mathrm{OL}=$ oligodendrocyte; PIANO $=$ Platform for Integrated Analysis of Omics data; PPMS = primary progressive MS; RRMS = relapsing-remitting MS; Sup = conditioned medium from B-cell cultures; $\mathbf{U C}=$ ultracentrifugation; $\mathbf{W M}=$ white matter.

B cells are important in the pathogenesis of MS, including B-cell functions unrelated to production of immunoglobulins (Igs). The degree of damage to subpial cortical gray matter (GM) in MS is reportedly directly proportional to the intensity of inflammatory meningeal lesions often described as $\mathrm{B}$ cell rich. ${ }^{1,2}$ We hypothesize that $\mathrm{B}$ cells entering the meninges and CSF from the circulation could release factors within the intrathecal space, causing damage to oligodendrocytes (OLs)/myelin and neurons/axons independent of Ig and/or complement and leading to damage characteristic of MS in the underlying cortical GM.

To investigate the effector role of B cells in MS, we tested medium (Sup) from cultures of B cells from blood of untreated patients with MS for toxicity to OLs and neurons in culture. MS Sup were cytotoxic to rat OLs and to rat and human neurons in vitro, whereas those from normal controls (NCs) produced little to no toxicity. ${ }^{3,4}$ MS B-cell Sup were not toxic to astroglia or microglia in these cultures. ${ }^{3}$ Killing is independent of complement and does not correlate with Sup levels of IgG, IgM, or any single or combination of a large number of cytokines and other proteins. ${ }^{4}$ Death of OLs and neurons involved apoptosis and was caused by 1 or more factors with a molecular weight greater than $300 \mathrm{kDa} .{ }^{4}$ In the present study, we investigate the nature of the toxic factor(s) by determining the effects of exosome-enriched (Ex-En) fractions isolated from MS Sup compared with NC Sup. using solvent precipitation, ultracentrifugation (UC), or immunoprecipitation (IP). Three different methods were used to verify results, given the potential limitations of each method when used in isolation. Proteomics analysis was used to assess enrichment of B-cell exosomal proteins in Sup and differences between NC and MS.

\section{Methods}

\section{Standard protocol approvals, registrations, and patient consent}

Blood was obtained with informed consent from patients with relapsing-remitting MS (RRMS) and matched controls of comparable age and sex at the Montreal Neurological Institute/McGill University and the Hospital of the University of Pennsylvania. B cells were obtained by positive selection for CD19 from peripheral blood of patients with RRMS and from NC, as previously described ${ }^{5,6}$ and as approved by the Ethics Review Board of the Montreal Neurological Institute and McGill University and the Institutional Review
Board at the University of Pennsylvania. Patients with MS had RRMS (at least 1 relapse in the previous 12 months) and were stable (no new symptoms or signs to suggest relapse in the previous 3 months). One patient had primary progressive MS (PPMS). None received corticosteroids or adrenocorticotropic hormone for at least 30 days or immunomodulating therapies for at least 6 months at the time of blood draw; patients treated with CD20-depleting agents, alamtizumab, or stem cell transplant were excluded.

\section{B-cell cultures}

After separation of blood mononuclear cells from $60-90 \mathrm{~mL}$ of peripheral blood from patients and matched NC using FicollHypaque (Sigma-Aldrich) gradient centrifugation, B cells were obtained by positive selection using anti-CD19 magneticactivated cell sorting (MACS) isolation beads (Miltenyi, \#130-050-301) as described. ${ }^{3-5}$ This typically resulted in isolation of $3-8 \times 10^{6} \mathrm{~B}$ cells, with purities $>95 \%$, as confirmed by flow analysis. B cells were cultured in 96-well plates for 3-4 days; Sup were collected, centrifuged at 2,000 $g$ for 5 minutes to remove cell debris, and frozen in aliquots at $-80^{\circ}$ until testing for toxicity. The $\mathrm{B}$ cells received no in vitro stimulation ("unstimulated" B cells) because we previously found that Sup from unstimulated MS B cells showed similar or greater OL toxicity than stimulated MS B cells. ${ }^{3}$ In initial experiments, the B cells were cultured in RPMI 1640 medium (Gibco) supplemented with $10 \%$ fetal bovine serum, $1 \%$ penicillin/streptomycin, and 1\% L-glutamine (Thermo Scientific); in subsequent experiments, cells were cultured in serum-free X-VIVO 10 defined medium (Lonza) supplemented with $1 \%$ penicillin/streptomycin.

\section{Glial cultures and cytotoxicity assay}

Cultures were prepared from the neonatal rat brain as previously described. ${ }^{3}$ Cultures from the third to fifth shakeoffs from the astroglial bed layer were used, resulting in cultures containing on average $35 \%-40 \%$ OLs, $35 \%-40 \%$ astroglia, and $15 \%$ microglia. Sup from B-cell cultures were diluted with OL medium (1:4) and incubated with cultures for 72 hours. Control medium was B-cell medium diluted 1:4 with OL medium. OL death was assessed by uptake of trypan blue. ${ }^{3}$ OL death in 1:4 B-cell:OL medium alone ranged from $4 \%$ to $14 \%$.

\section{Preparation of Ex-En fractions}

Ex-En fractions were prepared by 3 different methods, an exosome isolation kit, UC, and IP with antibodies to CD9, enriched in exosomes. 
1. For isolation of Ex-En fractions with the kit (Invitrogen \#4478359), B cells were grown in RPMI 1640 medium with $10 \%$ fetal bovine serum. Aliquots of $250 \mu \mathrm{L}$ of B-cell Sup from MS and NC in addition to medium were centrifuged at 2,000g for 30 minutes. The supernatants were removed and mixed with $125 \mu \mathrm{L}$ of isolation reagent. Samples were incubated at $4^{\circ}$ overnight and then centrifuged at 10,000 g for 1 hour to collect Ex-En fractions.

2. For isolation of Ex-En fractions by UC, B cells from MS and NC were grown in Lonza X-VIVO 10 serum-free medium. Aliquots of $250 \mu \mathrm{L}$ Sup and medium were centrifuged at $1000 \mathrm{~g}$ for 10 minutes; the pellet discarded and the supernatants were centrifuged at $10,000 \mathrm{~g}$ for 30 minutes. The resulting supernatants were diluted to $1 \mathrm{~mL}$ with Dulbecco's modified Eagle medium (DMEM) and centrifuged at $62,500 \mathrm{~g}$ for 2 hours. The pellet was suspended in 1 $\mathrm{mL}$ DMEM and washed 2 times at 62,500g for 2 hours.

3. For isolation of Ex-En fractions by IP, B cells from MS and NC were grown in Lonza X-VIVO 10 medium. From Sup and medium, $>300-\mathrm{kDa}$ fractions were prepared using Pall centrifugation filters. Sup were placed in prewashed Nanosep units (Pall Corp., Ann Arbor MI, \#OD0300C33) with membranes with a molecular weight cutoff of $300 \mathrm{kDa}$ and centrifuged at $14,000 \mathrm{~g}$ for 10 minutes. The toxic activity for OLs was in the $>300-\mathrm{kDa}$ retentates, with none in the filtrates of RRMS Sup and no toxicity above background in equivalent NC fractions. For IP,7 Protein A-Sepharose ${ }^{\circledR}$ beads (Sigma; P9424), $0.1 \mu \mathrm{g} / \mu \mathrm{L}$, were conjugated with $0.5 \mu \mathrm{g}$ of anti-CD 9 antibody (Abcam; ab2215) by incubating on ice for 30 minutes. The $>300-\mathrm{kDa}$ fractions were incubated with the conjugate for 2 hours on ice with mixing every 30 minutes. The incubate was centrifuged at $1,000 \mathrm{~g}$ for 1 minute, and the pellet was washed $3 \times$ in $500 \mu \mathrm{L}$ of PBS $\mathrm{pH}$ 7.4. The beads were eluted using $50 \mu \mathrm{L}$ of PBS $\mathrm{pH} 3$ to release the bound vesicles and centrifuged at $1,000 \mathrm{~g}$ for 1 minute to pellet the beads; the $\mathrm{pH}$ of the resulting supernatant was raised to 7.0 in a total volume of $350 \mu \mathrm{L}$.

\section{Proteomics analysis}

Analysis was performed in the Wayne State University Proteomics Facility Core. Albumin was removed from Sup proteins using ethanol precipitation. Samples were incubated with $39 \%$ ethanol at $25^{\circ} \mathrm{C}$ for 3 hours, followed by centrifugation at $17,000 \mathrm{~g}$ for 10 minutes. Supernatants were removed, and pellets were rinsed with $35 \%$ ethanol, dried, and then solubilized in $20 \mu \mathrm{L}$ of $125 \mathrm{mM}$ ammonium bicarbonate (AMBIC) and 1.25\% deoxycholate using Q Sonica Q800R. Samples were reduced with $5 \mathrm{mM}$ dithiothreitol (DTT) and alkylated with $15 \mathrm{mM}$ iodoacetamide (IAA). Excess IAA was quenched with an additional $5 \mathrm{mM}$ DTT. The proteins were then separated by sodium dodecyl sulfate-polyacrylamide gel electrophoresis (SDS-PAGE) using $10 \%$ polyacrylamide resolving/4\% polyacrylamide stacking gels-the samples were resolved a distance of $\sim 3.0 \mathrm{~cm}$ into the gels and then stained with Sypro Ruby Protein Stain (Invitrogen). For each sample, the band corresponding to albumin was discarded, and 6 other areas of the gel were pooled. The bands were digested overnight with sequencing-grade trypsin (Promega) in $40 \mathrm{mM} \mathrm{AMBIC,} 0.01 \%$ Protease Max (Promega), and $1 \mathrm{mM} \mathrm{CaCl}$. Following digestion, extracted peptides were separated by reversed-phase chromatography (Acclaim PepMap100 C18 column; Thermo Scientific), followed by ionization with the Nanospray Flex Ion Source (Thermo Scientific), and introduced into a Q Exactive mass spectrometer (Thermo Scientific). Abundant species were fragmented with high-energy collision-induced dissociation (HCD). MaxQuant software version 1.5.2.8 was used to search the mass spectrometry data against the Uniprot human complete database (April 17, 2016) and a database of common contaminant proteins. The match-between-runs feature was enabled, and just 1 peptide was required for quantification. All other settings were left at default values. Proteins that were flagged by MaxQuant as potential contaminants and the 32 most abundant proteins in a media-only sample were considered contaminants and not analyzed. Proteomic data analysis by protein fold change between MS and NC samples was performed in $\mathrm{R}$ version 3.2.3. Ontology enrichment analysis was performed using the R package PIANO. ${ }^{8}$

\section{Data availability}

Data will be shared upon request by any qualified investigator. The proteomics data for figure 4 and table are provided in supplemental table e-1 (links.lww.com/NXI/A107).

\section{Results}

\section{MS B cell-derived toxic factors are enriched in Ex-En fractions prepared by water exclusion precipitation}

We previously determined that factors with an apparent molecular weight of $>300 \mathrm{kDa}$ in Sup from cultured MS $B$ cells mediated death of rat OLs and neurons in culture. ${ }^{4}$ In those experiments, B cells were cultured in RPMI medium with $10 \%$ fetal bovine serum. We also showed that the $>300$ $\mathrm{kDa}$ fraction was toxic for neurons with minor amounts of neuronal toxicity in the $<300-\mathrm{kDa}$ fraction. ${ }^{2}$ Thus, for both OLs and neurons, cytotoxic effects of products released by MS $\mathrm{B}$ cells are found primarily in a fraction of $>300 \mathrm{kDa}$. This important finding led to the hypothesis that toxicity resided in extracellular microvesicles, possibly exosomes. To further test this hypothesis, we used the Invitrogen exosome isolation kit, based on a reagent with water exclusion properties, leading to precipitation of microvesicles. ${ }^{9}$ Analysis of Sup from 5 NC and 5 MS B-cell cultures indicated that OL toxicity was retained in the precipitated fraction, consistent with the presence of toxic factors in extracellular microvesicles (figure 1).

\section{MS B cell-derived toxic factors are enriched in Ex-En fractions prepared by UC}

To prepare samples free of bovine serum for more detailed analysis, we cultured the B cells in serum-free X-VIVO 10 
Table Differentially expressed components in MS and NC B-cell Sup identified by PIANO analysis of proteomics data

\begin{tabular}{|c|c|c|c|c|}
\hline Direction & Cellular component name & Proteins & FDR down in MS & FDR up in MS \\
\hline \multirow[t]{2}{*}{ Up MS } & Cell surface & 70 & 0.9999 & 0.0289 \\
\hline & GO:0009986 & & & \\
\hline \multirow[t]{2}{*}{ Up MS } & External side of the plasma membrane & 31 & 0.9999 & 0.0578 \\
\hline & GO:0009897 & & & \\
\hline \multirow[t]{2}{*}{ Down MS } & Ribosome & 31 & 0 & 1 \\
\hline & GO:0005840 & & & \\
\hline \multirow[t]{2}{*}{ Down MS } & Ribonucleoprotein complex & 87 & 0 & 1 \\
\hline & GO:1990904 & & & \\
\hline \multirow[t]{2}{*}{ Down MS } & Nucleolus & 60 & 0 & 1 \\
\hline & GO:0005730 & & & \\
\hline \multirow[t]{2}{*}{ Down MS } & Cytosolic ribosome & 27 & 0 & 1 \\
\hline & GO:0022626 & & & \\
\hline \multirow[t]{2}{*}{ Down MS } & Small ribosomal subunit & 18 & 0 & 1 \\
\hline & GO:0015935 & & & \\
\hline \multirow[t]{2}{*}{ Down MS } & Intracellular ribonucleoprotein complex & 86 & 0 & 1 \\
\hline & GO:0030529 & & & \\
\hline \multirow[t]{2}{*}{ Down MS } & Ribosomal subunit & 28 & 0 & 1 \\
\hline & GO:0044391 & & & \\
\hline \multirow[t]{2}{*}{ Down MS } & Cytosolic small ribosomal subunit & 17 & 0.0032111 & 1 \\
\hline & GO:0022627 & & & \\
\hline
\end{tabular}

Abbreviations: $\mathrm{FDR}=$ false discovery rate; $\mathrm{NC}=$ normal control.

defined medium supplemented with $1 \%$ penicillin/ streptomycin and $1 \%$ L-glutamine. OL toxicity in Sup from MS B cells compared with control B cells cultured in X-VIVO 10 defined medium (figure $2 \mathrm{~A}$ ) was similar to that obtained previously from $\mathrm{B}$ cells cultured in medium containing bovine serum. Toxicity was present in the extracellular vesicleenriched pellets (UC) obtained from MS Sup (figure 2B) following UC at 62,500g for 2 hours (see Methods). The average toxicity for MS UC fractions was $52.5 \%$ OL death compared with $22.5 \%$ for NC UC. After subtraction of the background value of $16 \%$ for the medium UC fraction, MS UC fractions induced 36\% OL death compared with $6.5 \%$ for NC.

MS B cell-derived toxic factors are enriched in Ex-En fractions prepared from MS B-cell Sup by IP with CD9 antibody

B cells were cultured for 72 hours in X-VIVO 10 serum-free medium. The $>300-\mathrm{kDa}$ fractions prepared from medium alone, 3 NC, and 3 MS Sup (2 RRMS and 1 PPMS) were immunoprecipitated with antibody to the exosomal marker CD9 conjugated to Protein A Sepharose. The IP fractions were tested for OL toxicity. Although the IP fractions from medium and NC showed some OL toxicity, after subtraction of the medium background, MS IP fractions from the 3 patients were 3-4-fold more toxic to OLs than NC (figure 3).

\section{Proteomic analysis of Sup from B-cell cultures} $\mathrm{B}$ cells were cultured for 72 hours in X-VIVO 10 serum-free medium. Samples from medium and Sup from 2 MS and 2 $\mathrm{NC}$ were prepared, and proteomic analysis was performed using mass spectrometry as described in Methods; 711 proteins were identified in at least 1 of the 4 nonmedium samples. Comparison of these results with published results for human B-cell exosomes ${ }^{10}$ showed that over 200 of the proteins detected in both MS and NC Sup were characteristic of Ex-En fractions (figure 4). MS and NC Sup share many common proteins. To understand differences in protein abundance between them, we tested cellular components for enrichment in 1 group relative to the other. MS Sup were enriched in proteins related to cell surface and the external side of the plasma membrane, and NC Sup were enriched in proteins related to ribosomes and splicesomes (PIANO, 10\% false discovery rate [FDR], table). Biological 


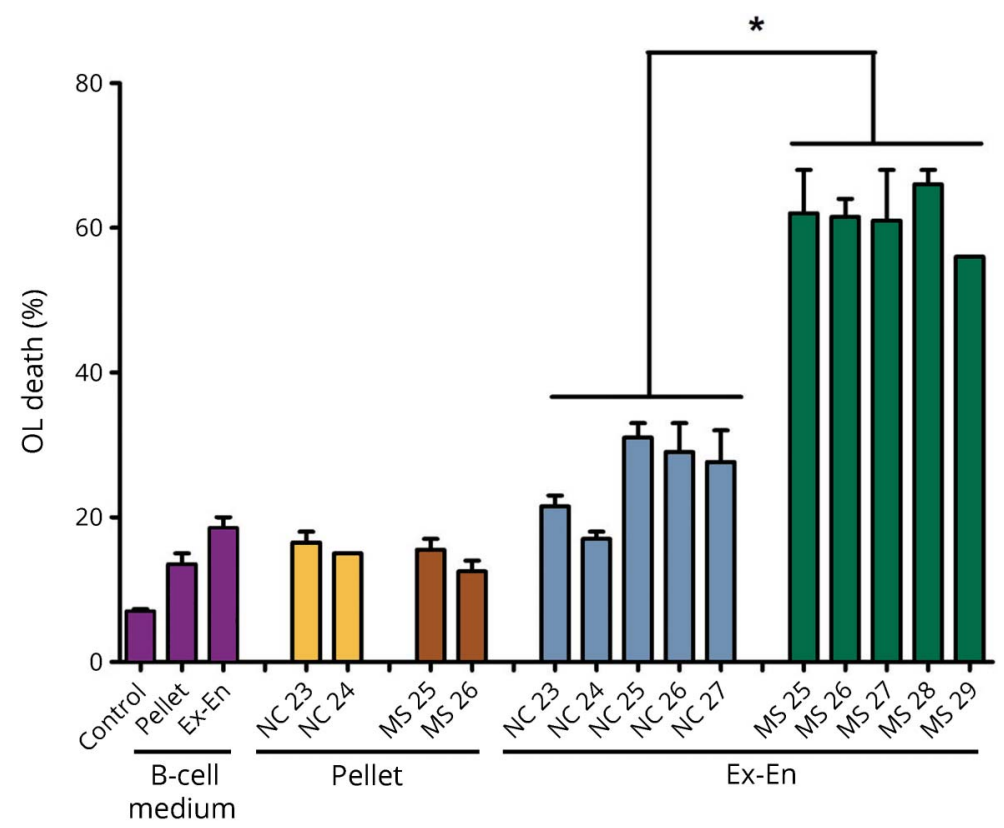

B-cell Sup from $5 \mathrm{MS}$ and $5 \mathrm{NC}$ were centrifuged at 2,000g for 30 minutes to remove cell debris; medium alone was processed in parallel as control. The supernatants were removed for isolation of Ex-En fractions; the pellets were suspended and tested for OL toxicity. The supernatants were mixed with isolation reagent. Samples were incubated at $4^{\circ}$ overnight and then centrifuged at 10,000g for 1 hour. The exosome-enriched precipitates, designated Ex-En, were tested for OL toxicity. The background value for NC Ex-En and MS Ex-En toxicity is the value for the toxicity of the medium Ex-En fraction (19\%); subtraction of that value gives a range of $-2 \%$ to $13 \%$ for NC ExEn and a range of $37 \%-43 \%$ for MS Ex-En. Values represent averages, $\mathrm{n}=2 \pm$ range; * $p<0.0001$ by analysis of variance with the Tukey post-test. Ex-En = exosome enriched; $\mathrm{NC}=$ normal control; OL = oligodendrocyte. processes and reactome pathways were also tested for enrichment. Antimicrobial peptides and keratinization proteins were increased in MS samples ( $<10 \% \mathrm{FDR}$, using reactome pathways) as were gliogenesis proteins (12.6\% FDR, biological processes).

\section{Discussion}

Our results show that MS B cells release factors toxic for OLs in extracellular microvesicle fractions with characteristics of exosomes. Each of the 3 independent methods of isolating ExEn fractions resulted in retention of OL toxicity in those fractions. As we reported, ${ }^{3}$ MS B-cell Sup did not induce toxicity in astroglia or microglia in our mixed glial cultures, and our initial results with Ex-En fractions so far support these observations, although the results have not been quantified. Future studies will examine the effects of Ex-En fractions on neurons as well. Proteomic analysis of Sup from both MS and NC showed the presence of a number of proteins characteristic of B-cell exosomes compared with an analysis of exosomes from a human B-cell line. ${ }^{10}$ A number of these proteins were also identified earlier ${ }^{11}$ in exosomes from human B cells, although depth of coverage was considerably lower in that analysis.

Our previous findings that MS B cells release non-Ig factors toxic to OLs and neurons in vitro support our hypothesis that peripheral B cells could enter the CSF and meninges and release factors that cause demyelination and damage OLs and neurons/axons in the underlying cerebral cortical GM. We know that B cells from both MS and NC release cytokines and Ig; however, when released in soluble form, these factors do not seem to be the toxic substances for OL, $\mathrm{OPC}$, and neuronal death in our in vitro assays. ${ }^{3,4}$ Identifying the factors responsible for the functional differences in products released by MS B cells compared with NC will increase our understanding of the role of $\mathrm{B}$ cells in the specific pathologic mechanisms underlying MS progression and potentially lead to more specific treatments for preventing progression.

Studies on the pathogenesis of MS highlight the complexity of this disease with increasing evidence of different pathogenic mechanisms involved in different components of the CNS: white matter (WM) and GM, both cortical and deep structures like thalamus and basal ganglia, and in different stages of disease. ${ }^{12,13}$ Part of the complexity arises from the multiple cell types of the immune system and the endogenous cells of the CNS involved in different clinical and pathologic phases of MS and in different parts of the CNS, that is, WM vs GM, particularly cortical GM.

B cells are now clearly known to be important in MS pathogenesis. ${ }^{14}$ Traditionally, B cells and their progeny, plasmablasts, and plasma cells were viewed as the source of antibodies directed against CNS constituents. ${ }^{15}$ There is very good evidence that Ig activation of complement is an important pathogenic mechanism in WM in relapsing MS. ${ }^{12,16}$ Production of Ig with binding capacity to CNS constituents by B-cell lineage has also been demonstrated. ${ }^{17}$ There have been major discoveries related to development and maturation of B cells and discoveries about B-cell subsets regarding their functions: naive vs memory $\mathrm{B}$ cells and regulatory vs 
Figure 2 Toxic factors are enriched in exosome-enriched fractions prepared from MS B-cell Sup by ultracentrifugation
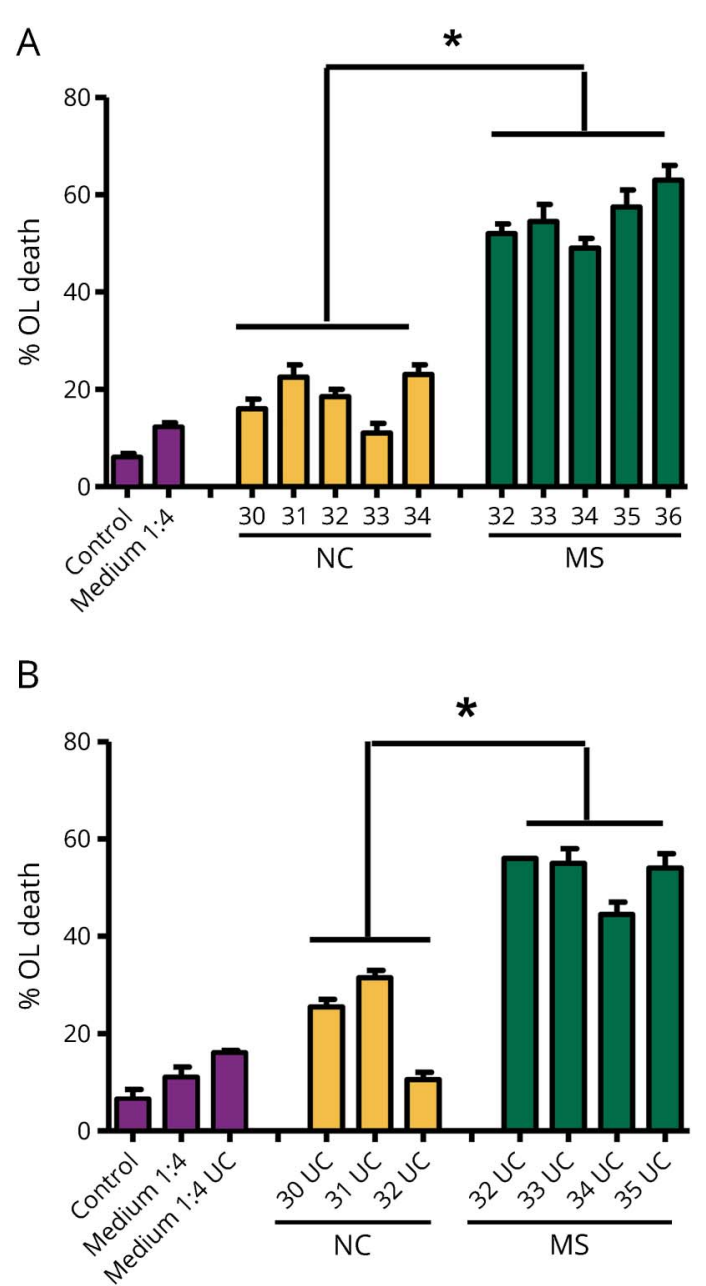

(A) B cells were cultured in serum-free X-VIVO 10 defined medium. Five MS Sup showed greater toxicity to OL than 5 NC Sup. These results were similar to those obtained previously from B cells cultured in medium containing bovine serum (Lisak et al. 2017). (B) Medium alone, 3 NC, and 4 MS Sup were centrifuged at 62,500g for 2 hours (see Methods); the pellets, enriched in extracellular vesicles, were suspended in DMEM, diluted 1:4 with OL medium, and tested for OL toxicity. The pellets from MS samples retained toxicity compared with the NC samples. The background value for NC UC and MS UC toxicity is the value for the toxicity of the medium UC fraction (16\%): subtraction of that value gives a range of $-5 \%$ to $16 \%$ for NC UC and a range of $29 \%-40 \%$ for MS UC. Values represent averages, $\mathrm{n}=2 \pm$ range; ${ }^{*} p$ $<0.0001$ by analysis of variance with the Tukey post-test. NC $=$ normal control; OL = oligodendrocyte; $\mathrm{UC}=$ ultracentrifugation

effector B cells. ${ }^{14}$ Effector B cells secrete a variety of cytokines, which can stimulate or suppress T-cell function. Within regulatory $\mathrm{B}$ cells, subpopulations use different cytokines from one another. Among effector B cells, some have regulatory effects as killer B cells, downregulating effector $\mathrm{T}$ cells by eliminating them rather than regulating T-cell activities. Others regulate via secretion of downregulatory cytokines including IL-10, IL-21, and IL-35. In addition, there is a reappreciation of $\mathrm{B}$ cells as highly efficient and specific antigen-presenting cells. ${ }^{18,19}$ The major early effect of B-cell depleting therapies in MS, rituximab
Figure 3 Toxic factors are enriched in exosome-enriched fractions prepared from MS B-cell Sup by immunoprecipitation with CD9 antibody

A. IP fractions: Raw data

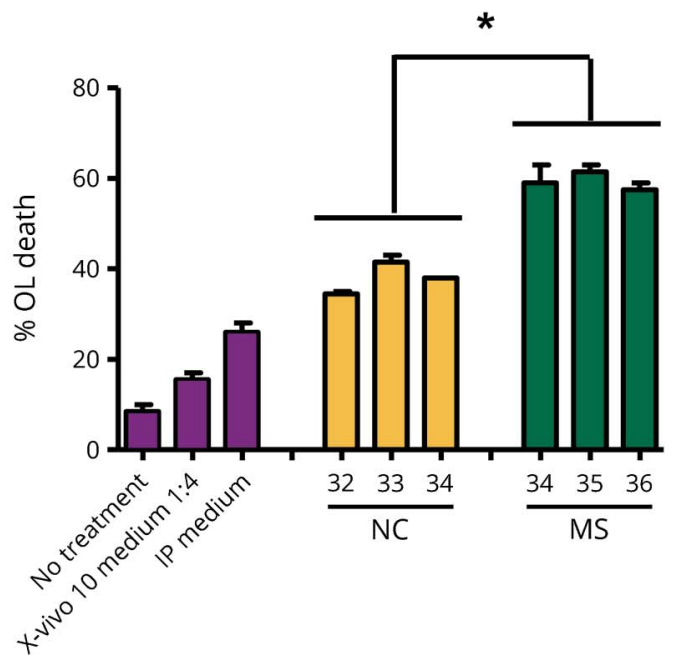

B. IP fractions: IP medium subtracted

*

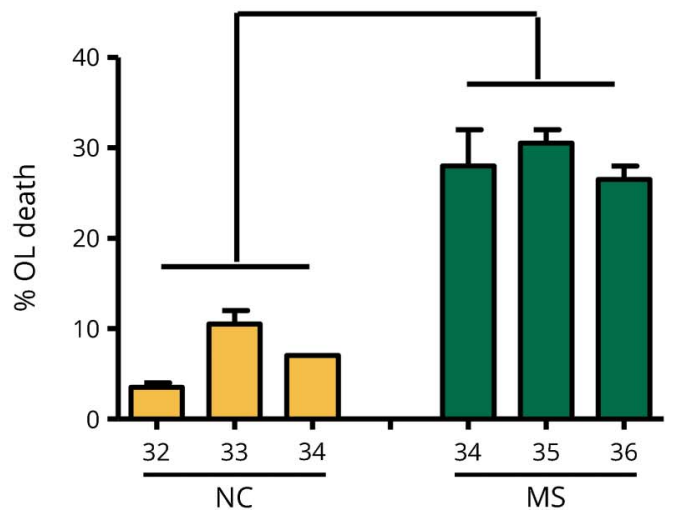

The $>300-k D a$ fractions prepared from medium alone, 3 NC, and 3 MS Sup were incubated with antibody to the exosomal marker CD9 conjugated to Protein A Sepharose. In the MS samples, 2 were RRMS and 1 was PPMS (MS36). Immunoprecipitates were tested for OL toxicity. Although the IP medium sample alone and IP NC fractions showed some OL toxicity (A), after subtraction of the medium background, MS IP fractions from each of the 3 patients with MS were 3-4-fold more toxic to OL than NC IP fractions (B). Values represent averages, $\mathrm{n}=2 \pm$ range; ${ }^{*} p<0.002$ by analysis of variance with the Tukey post-test. IP = immunoprecipitation; NC = normal control; OL = oligodendrocyte; PPMS = primary progressive MS; RRMS = relapsing-remitting MS.

and ocrelizmab as 2 examples, seems related to rapid shutting down of the abnormal blood-brain barrier because the clinical and imaging changes occur before any significant changes in serum Ig levels. ${ }^{14}$ In a study of B and T cells in the CSF in patients who received rituximab, there was a decrease in both B cells and T cells. ${ }^{18}$ The importance of $B$ cells in pathogenesis of MS is further supported by the findings that virtually all the approved disease-modifying therapies have an effect on B-cell numbers, trafficking, and/ or function. ${ }^{14}$ 
Figure 4 Venn diagram for B-cell Sup proteins compared with proteins from exosome-enriched fractions from a human B-cell line

A

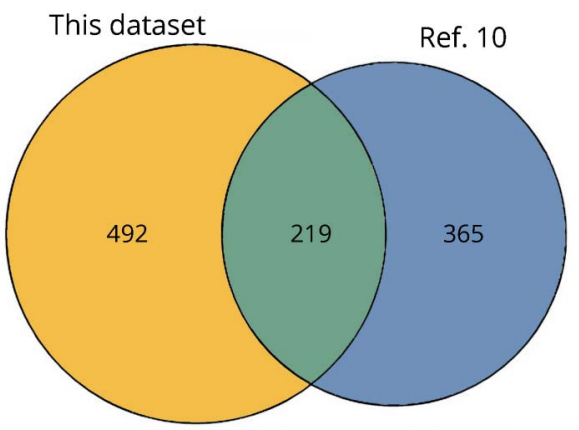

\begin{tabular}{|c|}
\hline $\begin{array}{l}\text { Representative proteins common to B-cell } \\
\text { supernatants and B-cell exosomes }\end{array}$ \\
\hline $\begin{array}{l}\text { Annexins } \\
\text { ATP-citrate synthase } \\
\text { B-cell antigen receptor complex activating protein* } \\
\text { CD20* } \\
\text { Complement C(3) } \beta^{*} \\
\text { Heat shock protein } 90 \\
\text { Immunoglobulin peptide chains* } \\
\text { L-lactate dehydrogenase A chain } \\
\text { Macrophage migration inhibitory factor* } \\
\text { MHC class I and II* } \\
\text { Pro-IL-16* } \\
\text { Proteasomal subunits } \\
\text { 14-3-3 protein }\end{array}$ \\
\hline
\end{tabular}

(A) Venn diagram. (B) The chart shows examples of representative proteins and groups of proteins from the 219 proteins common to both the B-cell Sup proteins and the exosome-enriched fractions from the human B-cell line, ${ }^{10}$ including both common exosomal markers and B cell-enriched proteins $\left(^{*}\right)$.

Some cortical GM damage may represent the effects of demyelination and axonal damage in the underlying WM, but this does not seem to explain much of the subpial cortical damage. ${ }^{20}$ The extent of meningeal inflammation found at autopsies associated with the severity of cortical pathology, with loss of oligodendroglia and neurons, along with microglial activation, and with more aggressive progression of disease. $^{1,2}$ The nature of the cortical GM damage seems to be unique to MS, as such changes are not seen in cortical GM underlying meningeal inflammation in other CNS disorders. ${ }^{20}$ These lesions, also described as type III cortical lesions, ${ }^{21}$ are compatible with diffusion of a factor from the meninges and/or CSF into the underlying cortex. Although autoantibodies to 1 or more constituents of the cortical GM might be involved, there is no evidence for Ig or activated complement deposited in these lesions. ${ }^{22}$ We demonstrated that Sup of peripheral blood B cells from MS patients contain 1 or more factors that are secreted or released, which are toxic in vitro to rat OLs and rat and human neurons, ${ }^{3,4}$ but not to astrocytes or microglia. Indeed microglia seem to undergo changes in appearance suggesting reactivity. B-cell cultures do not require in vitro stimulation to produce this effect, and Sup from cultured B cells from normal individuals produce little or no toxicity. ${ }^{3,4}$ In both our studies, there was no correlation with the very low levels of IgG and IgM, and our experiments use serum heated so as to inactivate complement pathways. We found no correlation with very low levels of cytokines and other related proteins, including those associated with $\mathrm{B}$ cells, ${ }^{3,4}$ in these cultures, which are not stimulated in vitro. ${ }^{6}$ As the next steps to characterize the toxic factor(s), we observed that the toxic activity for both OLs and neurons was in a $>300-\mathrm{kDa}$ fraction with a small amount of toxic effect on neurons in a $<300-\mathrm{kDa}$ fraction as well. ${ }^{4}$ Our current experiments suggest that microvesicles, likely exosomes, are involved in OL killing.

There is increasing interest in exosomes as important mediators of both autocrine and paracrine cell-cell interactions, ${ }^{23}$ including within the CNS. ${ }^{24,25}$ Exosomes are cell-derived microvesicles generally $30-100 \mathrm{~nm}$ in diameter, although the exact size range is still open to debate. ${ }^{23}$ They consist of a membrane derived from intracellular membranes of the cell of origin and a "cargo," which includes other proteins, lipids, and both miRNA and other RNAs. The cargo may differ based on the cell of origin. ${ }^{23}$ If the toxic effects are mediated by exosomes, lipids and miRNA, in addition to proteins, are potential toxic factors. Exosomes have been reported to be present in CSF of patients with MS, but the cellular source of those exosomes is not yet understood. ${ }^{26,27}$ Proteomic analysis of CSF exosomes shows different patterns in MS vs neuromyelitis optica spectrum disorder. ${ }^{28}$ Lipidomic analysis of MS plasma exosomes has detected sulfatide. ${ }^{29}$ Both miRNA and lipids, including species of ceramide, are also detected in CSF, and ceramide appears to have toxic effects on neuronal mitochondria function. ${ }^{30}$ Both normal and neoplastic $\mathrm{B}$ cells are known to release exosomes, ${ }^{10,11,31}$ but nothing is really known about exosomes from B cells of patients with MS. In addition to potential toxic effects of lipids that are known to be exosome "cargo," miRNA has potential toxic effects by affecting OLs and neuronal survival by inhibiting antiapoptotic cell activity or favoring apoptosis. ${ }^{32,33}$ It is possible that cytokines within the exosomes, and therefore not detected when we analyzed the Sup, could be mediators of OL and neuronal toxicity. ${ }^{34} \mathrm{~B}$ cells produce a wide variety of cytokines and when stimulated those from patients with MS produce more proinflammatory cytokines, but less IL-10, than normal individuals. ${ }^{6,35}$ Other potential components of B-cell exosome "cargo" with possible toxic effects would be proteins derived from Epstein-Barr virus, human endogenous retrovirus, ${ }^{36,37}$ or prion-like proteins that affect protein folding in the target cells, ${ }^{38}$ some known to be associated with B cells. ${ }^{39}$ It is possible, although we believe unlikely, that the exosomes from B cells of patients with MS lack or have reduced amounts of a growth factor important for OLs and neuronal survival in vitro leading to death by apoptosis. ${ }^{40}$

Our initial proteomic analysis of Sup from MS and NC, although from a limited number of samples, suggests that there may be differences in the types and cargo of exosomes from MS compared with NC. Extension of these findings will require investigation of whether the toxic factors reside in 
exosomes or another type of vesicle and analysis of the protein, lipid, and miRNA content of the vesicles in a larger number of samples.

\section{Author contributions}

J.A. Benjamins: data acquisition, drafting/revising the manuscript, study concept or design, analysis or interpretation of data, statistical analysis, and study supervision; accepts responsibility for conduct of research, will give final approval. L. Nedelkoska: data acquisition, study concept or design, analysis or interpretation of data, acquisition of data and conducted experiments published in this article. H. Touil: data acquisition, study concept or design, contribution of vital reagents/tools/patients, and conducted experiments published in the article. P.M. Stemmer: data acquisition, drafting/ revising the manuscript, analysis or interpretation of data. N.J. Carruthers: data acquisition, analysis or interpretation of data, acquisition of data, and statistical analysis. B. Jena: drafting/ revising the manuscript and analysis or interpretation of data. A. Naik: analysis or interpretation of data, data analysis, figure making, study sponsor, and data analysis. A. Bar-Or: data acquisition, drafting/revising the manuscript, study concept or design, analysis or interpretation of data, contribution of vital reagents/tools/patients, study supervision, and obtaining funding. R.P. Lisak: data acquisition, drafting/revising the manuscript, study concept or design, analysis or interpretation of data, study supervision, and obtaining funding.

\section{Acknowledgment}

The authors acknowledge helpful discussion with Dr. Jack Antel and Dr. Hans Lassmann regarding the possible role of human endogenous retrovirus in multiple sclerosis.

\section{Study funding}

This work was funded by the USA National Multiple Sclerosis Society (RPL, JAB, AB-O), the Melissa and Paul Anderson Endowment at the University of Pennsylvania (AB-O), the Research Foundation of the MS Society of Canada (AB-O, HT), and the Parker Webber Chair in Neurology Endowment (DMC Foundation/Wayne State University School of Medicine; RPL). The authors acknowledge the assistance of the Wayne State University Proteomics Core that is supported through NIH grants P30 ES020957, P30 CA 022453, and S10 OD010700.

\section{Disclosure}

J.A. Benjamins served as associate editor of the Journal of Neuroscience Research and the textbook Basic Neurochemistry; served on the editorial board of International Journal of Developmental Neuroscience; and received research support from the Detroit Medical Center Foundation and NMSS. L. Nedelkoska received research support from the NMSS. H. Touil received research support from the MS Society of Canada. P.M. Stemmer received research support from CURES, University Research Stimulation, and OVPR/ CURES. N.J. Carruthers, B. Jena, and A. Naik report no disclosures. A. Bar-Or served on the scientific advisory board of
Receptos-Celgene, Sanofi/Genzyme, Roche/Genentech, Novartis, GSK, Atara Therapeutics, Guthy-Jackson Greater Good Foundation, and Immune Tolerance Network; received travel funding and/or speaker honoraria from ReceptosCelgene, Roche/Genentech, Novartis, Sanofi-Genzyme, and GSK; served on the editorial board of Neurology, Clinical and Experimental Neuroimmunology; consulted for ReceptosCelgene, Roche/Genentech Novartis, Sanofi-Genzyme, GSK and Atara Therapeutics; and received research support from Novartis, Genzyme-Sanofi, and Biogen. R.P. Lisak served on the scientific advisory boards of Syntimmune, Alexion, Argenx, Novartis, NMSS, Myasthenia Gravis Foundation of America, and Guillain-Barre Syndrome/CIDP Foundation; received speaker honoraria from Teva; served as section editor of Neuroimmunology, Clinical Neuropharmacology; served on the editorial board of Immunology Research; received publishing royalties from Blackwell and Oxford; consulted for GLG, Insight, AlphaSites, Slingshot, Informa Pharma, bioStrategies, Novartis, and Argenx; served on the speakers' bureau of Teva; is chair of the clinical advisory committee of the NMSS; is on the board of governors: Research Grants Committee and Centers of Excellence Committee of the Medical Advisory Committee of the GBS/ CIDP Foundation and Grants Committee of the Myasthenia Gravis Foundation of America; and received research support from Teva, Alexion, Genentech, Novartis MedImmune, Chugai, Ra, MedDay, and Argenx paid to Wayne State University. Disclosures available: Neurology.org/NN.

\section{Publication history}

Received by Neurology: Neuroimmunology \& Neuroinflammation October 22, 2018. Accepted in final form January 16, 2019.

\section{References}

1. Bevan RJ, Evans R, Griffith L, et al. Meningeal inflammation and cortical demyelination in acute multiple sclerosis. Ann Neurol 2018;84:829-842.

2. Magliozzi R, Howell OW, Nicholas R, et al. Inflammatory intrathecal profiles and cortical damage in multiple sclerosis. Ann Neurol 2018;83:739-755.

3. Lisak RP, Benjamins JA, Nedelkoska L, et al. Secretory products of multiple sclerosis B cells are cytotoxic to oligodendroglia in vitro. J Neuroimmunol 2012;246:85-95.

4. Lisak RP, Nedelkoska L, Benjamins JA, et al. B cells from patients with multiple sclerosis induce cell death via apoptosis in neurons in vitro. J Neuroimmunol 2017, 309:88-99.

5. Duddy ME, Alter A, Bar-Or A. Distinct profiles of human B cell effector cytokines: a role in immune regulation? J Immunol 2004;172:3422-3427.

6. Bar-Or A, Fawaz L, Fan B, et al. Abnormal B-cell cytokine responses a trigger of T-cellmediated disease in MS? Ann Neurol 2010;67:452-461.

7. Jena BP, Stemmer PM, Wang S, Mao G, Lewis KT, Walz DA. Human platelet vesicles exhibit distinct size and proteome. J Proteome Res 2017;16:2333-2338.

8. Väremo L, Nielsen J, Nookaew I. Enriching the gene set analysis of genome-wide data by incorporating directionality of gene expression and combining statistical hypoth eses and methods. Nucleic Acids Res 2013;41:4378-4391.

9. Helwa I, Cai J, Drewry MD, et al. A comparative study of serum exosome isolation using differential ultracentrifugation and three commercial reagents. PLoS One 2017; 12:e0170628.

10. Buschow SI, van Balkom BW, Aalberts M, Heck AJ, Wauben M, Stoorvogel W. MHC class II-associated proteins in B-cell exosomes and potential functional implications for exosome biogenesis. Immunol Cell Biol 2010;88:851-856.

11. Wubbholts R, Leckie R, Veenhuizen PT, et al. Proteomic and biochemical analysis of human B cell-derived exosomes. J Biol Chem 2003;278:10963-10972.

12. Lassmann H, Brück W, Lucchinetti CF. The immunopathology of multiple sclerosis an overview. Brain Pathol 2007;17:210-218.

13. Kuhlmann T, Ludwin S, Prat A, Antel J, Brück W, Lassmann H. An updated histological classification system for multiple sclerosis lesions. Acta Neuropathol 2017;133: 13-24.

14. Li R, Patterson K, Bar-Or A. Reassessing B cell contributions in multiple sclerosis. Nat Immunol 2018;19:696-707. 
15. Hohlfeld R, Dornmair K, Meinl E, Wekerle H. The search for the target antigens of multiple sclerosis, part 2: CD8+ T cells, B cells, and antibodies in the focus of reversetranslational research. Lancet Neurol 2016;15:317-331.

16. Storch MK, Piddlesden S, Haltia M, Iivanainen M, Morgan P, Lassmann H. Multiple sclerosis: in situ evidence for antibody- and complement-mediated demyelination. Ann Neurol 1998;43:465-471.

17. Blauth K, Soltys J, Matschulat A, et al. Antibodies produced by clonally expanded plasma cells in multiple sclerosis cerebrospinal fluid cause demyelination of spinal cord explants. Acta Neuropathol 2015;130:765-781.

18. Cross AH, Stark JL, Lauber J, Ramsbottom MJ, Lyons JA. Rituximab reduces B cells and $\mathrm{T}$ cells in cerebrospinal fluid of multiple sclerosis patients. J Neuroimmunol 2006; 180:63-70.

19. Jelcic I, Al Nimer F, Wang J, et al. Memory B cells activate brain-homing, autoreactive CD4(+) T cells in multiple sclerosis. Cell 2018;175:85-100.

20. Lassmann H. Cortical lesions in multiple sclerosis: inflammation versus neurodegeneration. Brain 2012;135:2904-2905.

21. Peterson JW, Bö L, Mörk S, Chang A, Trapp BD. Transected neurites, apoptotic neurons, and reduced inflammation in cortical multiple sclerosis lesions. Ann Neurol 2001;50:389-400.

22. Brink BP, Veerhuis R, Breij EC, van der Valk P, Dijkstra CD, Bö L. The pathology of multiple sclerosis is location-dependent: no significant complement activation is detected in purely cortical lesions. J Neuropathol Exp Neurol 2005;64:147-155.

23. Shah R, Patel T, Freedman JE. Circulating extracellular vesicles in human disease. N Engl J Med 2018;379:2180-2181.

24. Fröhlich D, Kuo WP, Frühbeis C, et al. Multifaceted effects of oligodendroglial exosomes on neurons: impact on neuronal firing rate, signal transduction and gene regulation. Philos Trans R Soc Lond B Biol Sci 2014;369:20130510.

25. Yuma K, Igarashi Y. Physiological and pathological roles of exosomes in the nervous system. Biomol Concepts 2015;7:53-68.

26. Selmaj I, Mycko MP, Raine CS, Selmaj KW. The role of exosomes in CNS inflammation and their involvement in multiple sclerosis. J Neuroimmunol 2017;306: $1-10$.

27. Blonda M, Amoruso A, Martino T, Avolio C. New insights into immune cell-derived extracellular vesicles in multiple sclerosis. Front Neurol 2018;9.604.
28. Lee J, McKinney KQ, Pavlopoulos AJ, et al. Exosomal proteome analysis of cerebrospinal fluid detects biosignatures of neuromyelitis optica and multiple sclerosis. Clin Chim Acta 2016;462:118-126.

29. Moyano AL, Li G, Boullerne AI, et al. Sulfatides in extracellular vesicles isolated from plasma of multiple sclerosis patients. J Neurosci Res 2016;94:1579-1587.

30. Vidaurre OG, Haines JD, Katz Sand I, et al. Cerebrospinal fluid ceramides from patients with multiple sclerosis impair neuronal bioenergetics. Brain 2014;137: 2271-2286.

31. McLellan AD. Exosome release by primary B cells. Crit Rev Immunol 2009;29: 203-217.

32. Kashyap D, Tuli HS, Garg VK, Goel N, Bishayee A. Oncogenic and tumor-suppressive roles of MicroRNAs with special reference to apoptosis: molecular mechanisms and therapeutic potential. Mol Diagn Ther 2018;22:179-201.

33. Li JS, Yao ZX. MicroRNAs: novel regulators of oligodendrocyte differentiation and potential therapeutic targets in demyelination-related diseases. Mol Neurobiol 2012; 45:200-212.

34. Selmaj K, Raine C, Farooq M, Norton W, Brosnan C. Cytokine toxicity against oligodendrocytes. J Immunol 1991;147:1522-1529.

35. Duddy M, Niino M, Adatia F, et al. Distinct effector cytokine profiles of memory and naive human B cell subsets and implication in multiple sclerosis. J Immunol 2007;178: 6092-6099.

36. Perron $\mathrm{H}$, Lazarini $\mathrm{F}$, Ruprecht $\mathrm{K}$, et al. Human endogenous retrovirus (HERV)-W ENV and GAG proteins: physiological expression in human brain and pathophysiological modulation in multiple sclerosis lesions. J Neurovirol 2005;11:22-33.

37. Kremer D, Schichel T, Förster M, et al. Human endogenous retrovirus type W envelope protein inhibits oligodendroglial precursor cell differentiation. Ann Neurol 2013;74:721- 32.

38. Fevrier B, Vilette D, Archer F, et al. Cells release prions in association with exosomes. Proc Natl Acad Sci USA 2004;101:9683-9688.

39. Kane SJ, Farley TK, Gordon EO, et al. Complement regulatory protein factor $\mathrm{H}$ is a soluble prion receptor that potentiates peripheral prion pathogenesis. J Immunol 2017;199:3821-3827.

40. Kerschensteiner M, Stadelmann C, Dechant G, Wekerle H, Hohlfeld R. Neurotrophic cross-talk between the nervous and immune systems: implications for neurological diseases. Ann Neurol 2003;53:292-304. 


\section{Neurology \\ Neuroimmunology \& Neuroinflammation}

Exosome-enriched fractions from MS B cells induce oligodendrocyte death

Joyce A. Benjamins, Liljana Nedelkoska, Hanane Touil, et al.

Neurol Neuroimmunol Neuroinflamm 2019;6;

DOI 10.1212/NXI.0000000000000550

This information is current as of April 9, 2019

\section{Updated Information \& Services}

References

Subspecialty Collections

Permissions \& Licensing

\section{Reprints}

including high resolution figures, can be found at:

http://nn.neurology.org/content/6/3/e550.full.html

This article cites 40 articles, 6 of which you can access for free at: http://nn.neurology.org/content/6/3/e550.full.html\#\#ref-list-1

This article, along with others on similar topics, appears in the following collection(s):

Autoimmune diseases

http://nn.neurology.org//cgi/collection/autoimmune_diseases

Multiple sclerosis

http://nn.neurology.org//cgi/collection/multiple_sclerosis

Information about reproducing this article in parts (figures,tables) or in its entirety can be found online at:

http://nn.neurology.org/misc/about.xhtml\#permissions

Information about ordering reprints can be found online:

http://nn.neurology.org/misc/addir.xhtml\#reprintsus

Neurol Neuroimmunol Neuroinflamm is an official journal of the American Academy of Neurology.

Published since April 2014, it is an open-access, online-only, continuous publication journal. Copyright

Copyright (C) 2019 The Author(s). Published by Wolters Kluwer Health, Inc. on behalf of the American

Academy of Neurology.. All rights reserved. Online ISSN: 2332-7812.

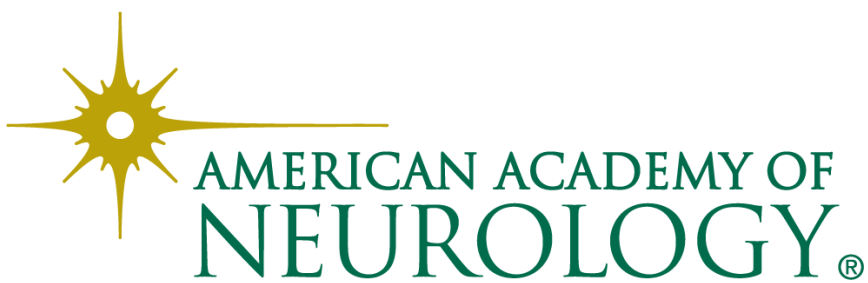

